\title{
Methods for Developing Well being in Learning Mathematics
}

\author{
Drd. Cătălina Anca Isofache 1 \\ Doctoral School Education Sciences, University from Bucharest \\ Bucharest / Romania
}

\begin{abstract}
The concern for pedagogy and the well-being of pupils which could amplify in a positive sense their school results entitles us to analyze during the scientific activity carried out in education sciences, under theoretical, methodological and empirical point of view, relevant activities related to the happiness in learning, with predilection in learning of mathematics. By using the experience of schools from the European Union and from worldwide, we will analyze the need to guide schools on the well-being of pupils during the educational activity. The happiness of the pupils, the decrease in their anxiety, must not decrease their level of training. If pupils shall imagine themselves over 10-15 years as future graduates, what future would they have if they did not learn mathematics, where might they be found in social life, what level would they have from an economic, intellectual point of view ? Mathematics develops formal operations that lead to the construction of thought, can stimulate pupils' affective life, and can motivate them to integrate into the adult society. There is supported the re-establishment of society on values, the development of a culture of success based on performance, work, talent, honesty and integrity. The implementation of these two guidelines, the first of a value-based society and the second of a happy environment among pupils, teachers and parents, generates the need to improve the educational strategies and to improve teachers' practices for harnessing the personal potential of pupils, providing quality in education.
\end{abstract}

Keywords: anxiety; educational strategies; mathematics; motivate; well-being. 


\section{International Conference on Research in Education}

5-7 APRIL , 2019

BARCELONA, SPAIN

\section{Optimizing the learning conditions}

\section{[12 points]}

In the learning process, there is a set of prerequisites of learning, which influence the production of learning and which generate a preparatory attitude of the pupil towards learning. In order for pupils to be trained to learn and to use their maximum potential, it is essential to create a state of curiosity, of pleasure of learning, of an emotional state without anxiety and stress. Creating a mental model of a mood that should influence positively the behavior of the pupil, the state of optimism in learning can be achieved through efficiency, creativity and a constructive way of thinking and action. The motivation of school and non-school learning is classified into "intrinsic motivation, characterized by the fact that it is triggered in the intimate structure of the pupil, supports from the inside the extrinsic learning and motivation, predominantly in teaching situations based on excessive authority, on constraint, on rigid systems of assessment"(Neacşu, 2015, p. 74).

The contemporary teacher has the unwritten task of controlling and guiding the set of learning motivations in his didactic activity, by knowing the pupils' personality and reporting their evolution to the educational program and to the motivational models of genetic, normative, circular-integrating models, of balance and coevolution, of Maslow's pyramid.

The concept of learning motivation is complex and its paradigmatic approaches (Middleton and Perks, 2014) consist in dynamism, connection with the goals of the activity, contextualization, modeling of the essential meanings. In the classroom of pupils, learning motivation is a dynamic system, under continuous transformation, cumulating the individual motivational impulses or responding to the social, family environment. That is why it is good to emphasize the connection between the purpose and the reason of learning, to progressively formulate goals, to customize them according to each classroom of pupils or according to each pupil's personality.

In addition to achieving a strong motivation for learning, optimizing the learning conditions involves building a material foundation proper for conducting the classes. The furniture from the classroom, its arrangement, the existence of computers during classes, of the auxiliary materials, generate a behavior in the learning activity. Inappropriate educational climate can be damaging to school success. The quality of classes is correlated 


\section{International Conference on Research in Education}

with the psycho-hygienic and ergonomic requirements of the classroom, with the existence of a comfort of temperature, humidity, lighting, etc..

\section{Blank line [12 points]}

Blank line [12 points]

1.1. The state of training for learning

Blank line [12 points]

Prerequisites of learning include a motivational set, attention, creating interest for learning, focusing on the content of learning. The state of training for learning involves a cognitive training, a psychological fitting and a staged training for the work carried out. The lack of a real concern for achieving a learning training state can generate negative effects in the learning process. As educators, we can look at situations from the perspective of the one who wants to learn or of the pupil we teach. Filtering stimuli and guiding them in an organized and appropriate way can make the learning process easier. Each type of knowledge requires a specific form of training, in order to achieve learning performances we combine procedural knowledge with the declarative one, the theoretical and practical explanations. Earlier acquisitions in the studied field influence greatly the learning process, thus for training learning there must be updated and reviewed the basic notions to be used in learning. As a rule, we cannot change pupils' ability to learn, but we can improve it by ensuring a simplification and the division of the subject into small sequences for those having learning difficulties and including didactic activities with high level of difficulty for those who learn faster by providing alternative routes of learning.

Learning training state can be achieved by influencing motivation, highlighting the significance of the content to be learned, improving pupils' confidence level regarding the acquiring of the content taught, and creating a positive learning atmosphere and working environment.

The triad of the learning training state consists of providing a psycho-hygienic and ergonomic climate, consisting in motivating those to be trained and checking previous acquisitions, see figure no. 1 .

Figure no. 1 Triad of the learning training state 


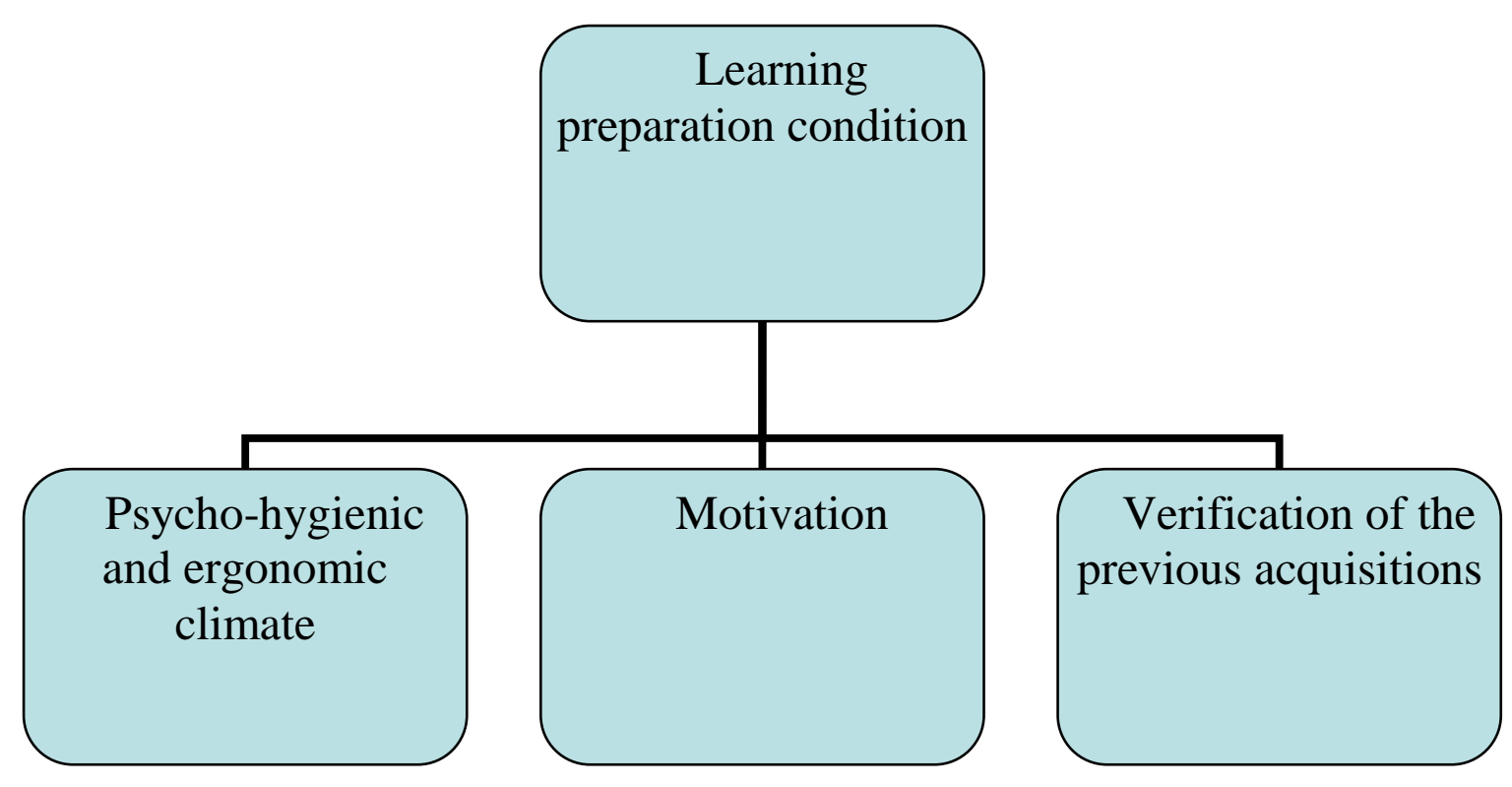

Blank line [12 points]

\subsection{Well-being in learning}

\section{Blank line [12 points]}

In the explanatory dictionary of the Romanian language state means "a situation in which someone or something is found, way, kind, look in which someone or something presents themselves." The word well as a noun is explained in the explanatory dictionary of the Romanian language by ,gratitude, happiness, welfare "(dexonline.net). Learning is defined by Professor Neacşu as "an activity having a psychological and pedagogical value, directly and indirectly guided and assessed by the educator, consisting in acquiring, transforming, accommodating, improving, reconstructing, conscious, progressive, voluntary and relatively interdependent fixing and reproducing of knowledge, skills and attitudes, synthetic of competencies "(Neacşu, 2015, p.15).

One of the projects taking place within the Faculty of Psychology and Educational Sciences of the University of Bucharest together with partners in Denmark aims at the well-being of children and pupils. As Lucian Ciolan, the dean of the aforementioned faculty states, "to learn and be successful in learning, in order to strengthen your learning, you need first of all to have a well-being." (http: /leaders.ro/newsfeed/lucian-ciolan, 2018). Well-being in learning is a complex concept that includes components that belong to 


\section{International Conference on Research in Education}

society and family, school, basic health needs. According to Dean Lucian Ciolan, in the Romanian school, pupils have to learn and much of the learning takes place under pressure, which can create unpleasant emotional consequences for longer term. A learning becomes successful if it can integrate three levels, cognitive, emotional and social, see figure no. 2. Young people, under the current economic context, should be prepared for a lifelong learning.

Figure no. 2 Levels of learning

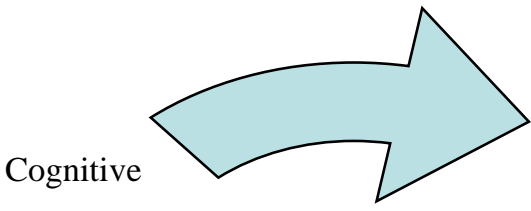

Emotional

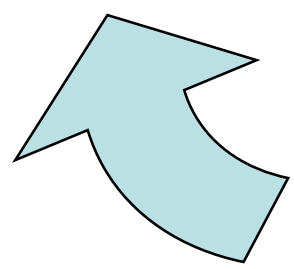

Social

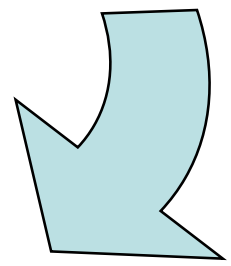

\section{Optimizing the learning of mathematics}

Learning mathematics in high school is a constant concern of educators, because in Romania, mathematics is a fundamental subject, being an examination subject at baccalaureate. In building a mathematics class, the training state of learning of mathematics requires the clear identification of the terms, concepts, the preparation of the necessary resources and materials, the establishment of the relations between meanings, senses of the mathematical formulas, determination of the rules of use, solving problems in mathematical language, forming an univocal context. In high school mathematics during the teaching process, the teacher provides rules for the construction and use of notions. Problem solving can represent a starting point in forming strategies based on critical 


\section{International Conference on Research in Education}

thinking, requiring the use of a cognitive activity associated with the use of the mind, creating a set of skills and attitudes. In learning mathematics, acquiring of knowledge, methods, models, comprehension of mathematical structures, transferring of what has been taught to a subject of mathematics, eg trigonometry to another subject of mathematics, eg mathematical analysis or to a subject from the curriculum of Mathematics and Sciences. The transfer of mathematical notions learned in new situations can be achieved to other subjects, eg economics, informatics, philosophy, etc. The most important connections in learning are metacognition, decision making and problem solving. Metacognition can become a learning generator by organizing and valorizing creative skills.

\subsection{Case study}

Studying the well-being in mathematics as a whole, of a pupil belonging to a classroom or of a classroom belonging to a school can be efficiently carried out through certain empirical research tools. One of these tools is the case study.

"As a rule, the case study starts, like any investigation, from a theoretical framework that is essential in data collection. Without a hypothesis or guiding ideas, the collection of information is minor. Follows the selection of cases and the specification of the analysis units (individual, situation, etc.) once with drafting the data collection protocol. Next, one proceesed to the the study of each case by interview, observation, test. Finally, relevant data are extracted in light of the start-up idea, there is changed the original theory and there are developed all the implications. The validity of the case study is partial. "(Yin, 1989).

The subjects of the empirical research conducted in the case study have been the pupils' classrooms of a theoretical college from the urban area. The variables that have been studied for an effective achievement of the learning state of mathematics and the wellbeing in mathematics are presented in table no. 1.

Table no. 1 Variables influencing the learning condition in mathematicss

\begin{tabular}{|l|l|l|}
\hline \multicolumn{1}{|c|}{ Variables / teacher } & \multicolumn{1}{|c|}{ Variables/ pupil } & \multicolumn{1}{c|}{ Variables/ classroom } \\
\hline Teacher's personality (P1) & Biophysical features ( E1) & Ergonomic conditions \\
\hline Scientific preparation level & Psycho-individual features & Psycho-hygienic \\
\hline
\end{tabular}


BARCELONA, SPAIN

\begin{tabular}{|c|c|c|}
\hline$(\mathrm{P} 2)$ & $(\mathrm{E} 2)$ & conditions \\
\hline Teacher's motivation (P3) & Age features ( E3) & Use of computer \\
\hline $\begin{array}{l}\text { Teacher's perfectioning level } \\
\text { (P4) }\end{array}$ & Family environment (E4) & Use of sheets \\
\hline $\begin{array}{l}\text { Psycho-pedagogical preparation } \\
\text { level (P5) }\end{array}$ & Empathy ( E5) & Use of didactic material \\
\hline Playful-imaginative spirit (P6) & $\begin{array}{l}\text { Positive relationships with the } \\
\text { others( E6 ) }\end{array}$ & Use of review schemes \\
\hline Creative, innovative spirit (P7) & $\begin{array}{l}\text { Awareness of the internal health } \\
\text { condition, of attention } \\
\text { ( E7 ) }\end{array}$ & Cohesion of pupils staff \\
\hline $\begin{array}{l}\text { Emotional-affective preparation } \\
\text { ( P8) }\end{array}$ & Self-awareness ( E8 ) & $\begin{array}{l}\text { Breaks time during } \\
\text { daily learning }\end{array}$ \\
\hline $\begin{array}{l}\text { The presence of certain well } \\
\text { defined purposes ( P9 ) }\end{array}$ & $\begin{array}{l}\text { Openness to new learning } \\
\text { experiences ( E9 ) }\end{array}$ & $\begin{array}{l}\text { Free time from the end } \\
\text { of the week }\end{array}$ \\
\hline
\end{tabular}

\subsection{Case study analysis}

The case study focused on the training state of learning and on the well-being of pupils and teachers during mathematics classes. The influence of these states over the learning outcomes was checked. Psycho-hygienic conditions are essential for a good conducting of the mathematics class. A pupil who does not rest enough, who uses excessively the mobile phone or uses the computer without reason, becomes anxious and cannot have a power of concentration and an increased attention during classes. This emerged from the dialogues with pupils' parents and with the pupils themselves. Ergonomic conditions have a lesser influence and are felt over time. For example, if pupils use furniture that is inappropriate for their age, after a period of time posture problems arise.

There are students who are preoccupied with science, physics, chemistry, astronomy, and robotics. It is quite important for them to become aware of the role of mathematics in science development and research. We present the opinion of Asanache Victor, a student 
of the Alexandru Ioan Cuza National College in Ploiesti. He talks about the role of mathematics in exploring cosmic space, because he wants to become astronaut. ( fig. 3 )

„Over time, the discovery of mathematics has helped mankind evolve and become the most advanced species on planet Earth. This science is the basis of the whole universe, its understanding and discoveries in the field, helping us to understand and "control" the environment.

In order to find out more about the purpose of this world, man decided to look up and try to understand what was there, beyond. One of the first to make an important discovery was the mathematician Eratostene of ancient Greece. He noticed that at the time of the summer solstice (June 21st) at 12:00, the sun is at the zenith in Assuan, and at the same time and date in the city of Alexandria, located about the same meridian as Assuan (difference of 2 degrees), the shade left by a tower represents $1 / 50$ of the circumference of a circle. This corresponds to an angle of approximately 7 degrees and 12 minutes. The distance between the two localities is about 5,000 stages (an ancient Greek state is about 185 meters), Eratostene determined that the circumference of the planet is about $50 \times 5000=252,000$ stages (approximately 39,690 km). Currently accepted value is 40,008 km. His discovery not only determined the Earth's (rather accurate) dimensions, but also its shape.

Eratostene's experiment was one of the first in which mathematics was applied with an element of the cosmic space, the Sun, to make an important discovery. 2000 years later, people use advanced mathematical concepts to leave their home and learn new information. NASA used the Apollo program to explore the moon with a lot of mathematics for navigation, trajectories and orbits. To reach the planet's natural satellite, three astronauts were traveling for 4 days in a command module that had a monthly module attached. They enrolled in the moon's orbit, one of them remained in the command module, and the other 2 used the module to moan. To return, the two were rising from the surface into the capsule they came to, and with the help of advanced mathematical calculations, they had to meet at fixed with the command module on the orbit. One of the cases in which orbital calculus proved to be critical in the survival of astronauts was the accident during the 13th Apollo mission, when the 3 were forced to abandon the command module following an explosion and try to live in the lunar module, which was not designed to be used throughout the entire mission. The Houston team of scientists 


\section{International Conference on Research in Education}

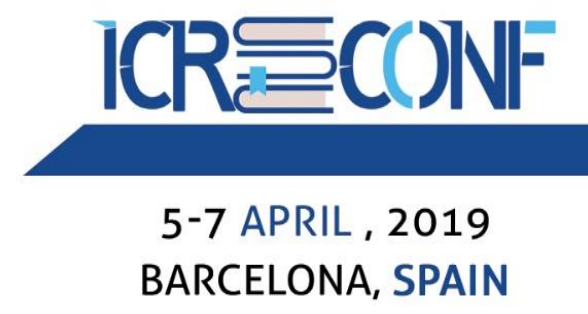

calculated day and night to discover a trajectory that would bring the crew alive back to Earth. Fortunately, math saved the life of the 3, the mission having a happy ending, even if it did not moon on the moon.

Every year there are important breakthroughs in mathematics. If in ancient times we were able to discover the nature of the world in which we live, and in the last century we reached the moon, who knows where our mathematics will take in the next decades?"

Figure no. 3 students who are preoccupied with science

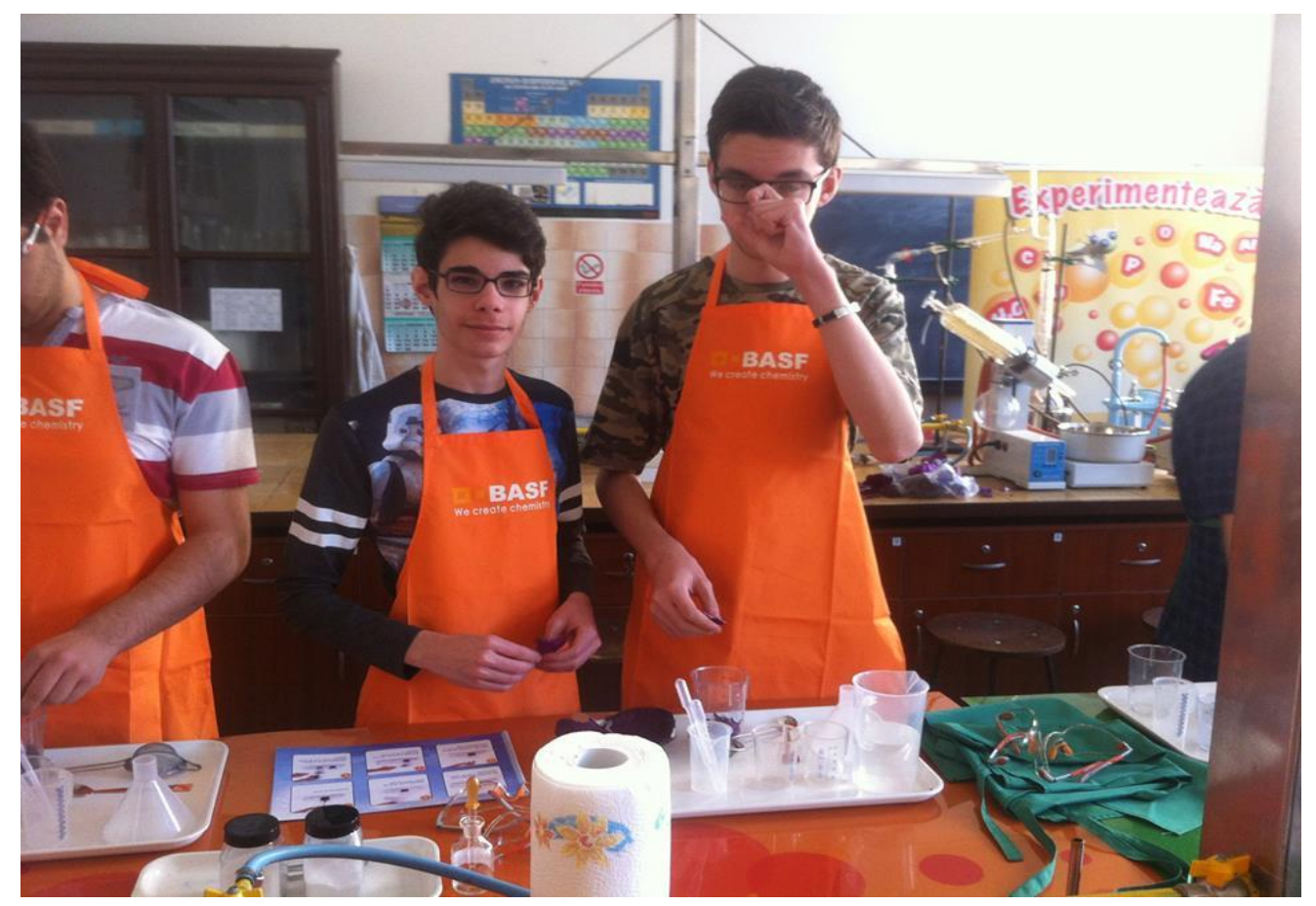

The teacher's personality turned out to be very significant for the training state of learning. Also, the presence of certain well defined learning outcomes has a great influence on the attention and participation to mathematics classes. For example, if some pupils are told what is the purpose and where is used a theoretical mathematical notion or a method of solving a problem, he increases his interest for the subject.

Below is done a scoring of the influence of some variables that can determine the state of well-being in mathematics and the training state of learning in mathematics. The grading scale is from 1 to 10 , in the ascending order of the positive influence over the two above mentioned states. In Diagram no. 1 are presented the values achieved for the influence of 


\section{International Conference on Research in Education}

the teacher in the training state of learning and in the state of well-being on mathematics. Teacher Features Codes are marked from P1 to P9 and can be read from Table 1.

Diagram no. 1 Scale of teacher's influence in the learning preparation condition/ well-being in mathematics

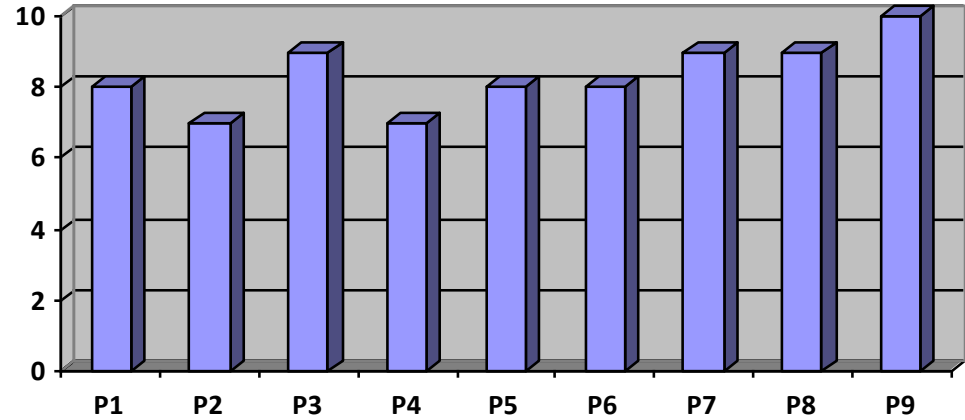

$\square$ Coloană 3-D 1

The teacher's role in providing the transfer of knowledge in mathematics has recorded an average of 8.44 .

The same thing was achieved also with the measurements of the influence of pupils' features over the learning training states and of well-being in mathematics class. Codes for pupils' studied features are marked from E1 to E9 in Table 1, and the scale of values associated with each feature analyzed in the case study is found in Diagram 2. The average achieved by pupils' features in the training state of learning is 6.88 .

Diagram no. 1 Scale of pupils' influence in the learning preparation condition/ well-being in mathematicss

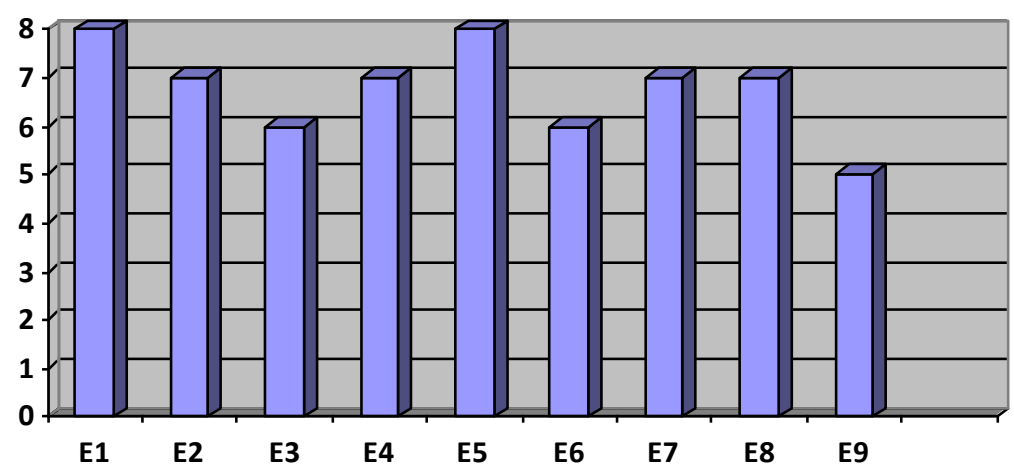




\section{International Conference on Research in Education}

The case study was conducted with pupils, teachers and parents of pupils who are interested in pursuing a higher education form and whose educational target consists in graduating the baccalaureate examination. The unanimous conclusion was that a systematic training, based on theoretical and practical reviews and the provision of a stock of knowledge during each class increases the pupil's confidence in fulfilling the working tasks, provides a calm and study-based climate and outlines the well-being of the partners from education, teacher and pupils.

\subsection{Conclusions}

According to Polya (1971), the teacher "has to help, not too much, nor too less, so that the pupil should be incumbent some of the work."

The didactic process is a complex way of communicating a school curriculum, using the learning mechanisms, the record of learning conditions, creating some thinking and creativity skills needed for the adaptation to the inherent changes from the social life. As teacher of mathematics, we aim to achieve the understanding of the role of designing the educational situation through the components: teaching, learning and assessment in mathematics. We propose ourselves: to analyze and investigate the existing connections, the influence and the significance of mathematicss with the seven curricular areas of the Romanian education; the correlation with the educational policies destined to optimization within the European Union. The school curriculum contributes to the development of an open thinking, ensuring objectivity, productivity, tenacity, perseverance, distributive attention and willingness to solve multiple tasks, achieving the rigor, order and elegance in problems solving, or in building some relevant theories and appropriate for the reference field (see D. Potolea, 2008, p.128). In our didactic research we will focus on a more complex educational dialectic and the personalities present in the educational process: teachers-pupils-parents should interact functionally with each other.

In the 20th century: learning was focused on "learning by doing" and "apprendre a etre"; in the 21st century: "learning by learning" and "learning by thinking" aiming at the desire and need to develop lifelong learning skills; the development of some higher mental 


\section{International Conference on Research in Education}

structures can be accomplished by the action of the subject, social mediation and cognitive learning.

School training= teaching, learning and assessment, which are in a permanent explicit and implicit interaction. Teaching represents the "art of teaching others", of sharing knowledge, of presenting a new subject; a complex structure of actions that trains pupils into learning a content with the help of the teacher.

The complex process of learning is an intellectual activity that cannot be accomplished by chance. The reference systems are very varied, so it is essential to find, starting with the well-being in mathematics class, those strategies, methods, techniques and criteria for learning optimization.

Blank line [12 points]

\section{Bibliography references:}

1. Căprioară, D. ( 2011 ). Predarea și învățarea matematicii. Studiul obstacolelor și al erorilor, București: Editura Universitară.

2. Cerghit, I. ( 2008). Sisteme de instruire alternative și complementare, Iași: Polirom.

3. Ciolan, L. (2002). „Reforma curriculară în învățământul liceal românesc: premise, politici, metodologii”, în E. Păun, D. Potolea, Pedagogie. Fundamentări teoretice și demersuri aplicative, Iași: Polirom.

4. Cucoș, C. ( 2002 ). Pedagogie, Iași: Polirom..

5. https://leaders.ro/newsfeed/lucian-ciolan-decanul-facultatii-de-psihologie.

6. https://www.digi24.ro/stiri/actualitate/educatie/scolile-evaluate-dupa-starea-de-bine-a-elevilor.

7. Kyndt, E., Donche, V. ( 2017). Higher Education Transition. Theory and Research, New York: Routeledge.

8. Marcus, S., David, T. , Predescu, I. ( 1987 ). Empatia și relația profesor-elev, București: Editura Academiei Române.

9. Neacșu, I. ( 2015 ).Metode și tehnici de învățare eficientă, Iași: Polirom.

10. Neacșu, I. (1999) ). Instruire și învățare, București: Editura Didactică si Pedagogică.

11. Negreț, I.D., Pânișoară, I.O. ( 2005 ). Știința învățării, Iași Polirom.

12. Pânişoară, I.O. ( 2009 ). Profesorul de succes, Iaşi: Polirom.

13. Potolea, D., Neacșu, I., Iucu, R., Pânișoară, I.O. ( 2008 ). Pregătirea psihopedagogică, Iași: Polirom.

14. Smith, P., Pellegrini, A.D. ( 2000). Psychology of Education, London: RouteledgeFalmer. 